\title{
Penerapan Pembelajaran Model STAD (Student Team Achievement Devision) Dengan Variasi Kuis untuk meningkatkan Prestasi belajar Mata Pelajaran IPS Terpadu Kelas IX ( Sembilan ) A MTs Negeri Kota Sorong Tahun Pembelajaran 2017/2018
}

\author{
Muhammad Abidin
}

MTs Negeri Kota Sorong

\begin{abstract}
Pembelajaran model kooperatif STAD dapat meningkatkan prestasi belajar. Bermain kuis dapat meningkatkan prestasi belajar siswa .Jika siswa belajar tentang materi Perang Dunia II serta pengaruhnya terhadap keadaan sosial, ekonomi, dan politik di Indonesia dengan model kooperatif STAD, maka prestasi belajar siswa akan meningkat dan dengan bermain kuis, maka prestasi belajar siswa akan meningkat.Penelitian tindakan kelas ini menerapkan model pembelajaran kooperatif STAD (Student Team Achievement Devisions) dengan variasi bermain kuis. Pembelajaran dengan kooperatif STAD memiliki keunggulan yang dapat mengatasi masalah yang ada. Karena dalam kooperatif STAD akan terjadi meningkatnya fungsi mental melalui percakapan dan interaksi lainnya, serta kerjasama antar siswa yang memiliki kemampuan yang heterogen. Begitu pula bermain kuis diyakini memiliki keunggulan menciptakan suasana pembelajaran yang mengasyikkan, karena berupa permainan tanya jawab antar kelompok. Dalam situasi demikian diharapkan siswa tidak akan mengantuk dan bosan belajar IPS Terpadu. Kegiatan bertanya dan menjawab adalah bentuk kegiatan berfikir, sedangkan belajar juga melalui proses berfikir.Sebagaimana layaknya penelitian tindakan kelas, maka penelitian ini akan dimulai dari siklus I yang pelaksanaannya melalui 4 (empat) tahap yaitu : perencanaan, tindakan, observasi, dan refleksi.Hasil pengamatan pembelajaran klasikal dari siklus I mencapai 54,22\%, siklus II mencapai $66,15 \%$, dan siklus III mencapai $84,61 \%$. Peningkatan tersebut menunjukkan peningkatan semangat belajar siswa dalam mengikuti pembelajaran IPS Terpadu.Hasil pengamatan pembelajaran kooperatif STAD dari siklus I mencapai 91,66\%, siklus II mencapai 92,85\%, dan siklus III mencapai 97,91\%. Peningkatan tersebut menunjukkan peningkatan semangat belajar siswa dalam mengikuti pembelajaran IPS Terpadu. Hasil pengamatan pembelajaran melalui kegiatan kuis dari siklus I mencapai 74,82\%, siklus II mencapai $86,17 \%$, dan siklus III mencapai $92,77 \%$. Peningkatan tersebut menunjukkan peningkatan semangat belajar siswa dalam mengikuti pembelajaran IPS Terpadu melalui kuis.Menerapkan model kooperatif STAD, diperlukan persiapan yang matang, terutama pada saat penilaian kelompok penjawab diperlukan dan mempersiapkan instrumen pengamatan beserta rubrik-rubrik yang jelas pada saat kegiatan kuis.
\end{abstract}

Keywords: klasikal, koperatif, dan kuis

Abstrak: Learning of STAD cooperative model can improve learning achievement. Quiz play can improve student learning achievement. If students learn about World War II material and its effects on social, economic and political conditions in Indonesia with the STAD cooperative model, student achievement will increase and by playing quizzes, student learning achievements will increase. This classroom action research implication STAD (Student Team Achievement Devisions) cooperative learning model with variations of quiz play. STAD cooperative learning has advantages that can overcome existing problems. Because in the STAD cooperative there will be an increase in mental functions through conversation and other interactions, as well as collaboration between students who have heterogeneous abilities. Similarly, playing quiz is believed to have the advantage of creating an exciting learning atmosphere, because it is a question and answer game between groups. In such situations it is expected that students will not be sleepy and tired of learning Integrated IPS. Asking and 
answering activities are a form of thinking activities, while learning is also through the process of thinking. As is the case with classroom action research, this research will begin from cycle I, which is carried out through 4 (four) stages: planning, action, observation and reflection. The results of classical learning observations from cycle I reached $54.22 \%$, cycle II reached $66.15 \%$, and cycle III reached $84.61 \%$. This increase shows an increase in the enthusiasm of students in participating in Integrated Social Studies learning. The results of the STAD cooperative learning observation from the first cycle reached $91.66 \%$, the second cycle reached $92.85 \%$, and the third cycle reached $97.91 \%$. This increase shows an increase in the enthusiasm of students in participating in Integrated Social Studies learning. Observations of learning through quiz activities from cycle I reached $74.82 \%$, cycle II reached $86.17 \%$, and cycle III reached $92.77 \%$. This increase shows an increase in students' enthusiasm for learning in participating in Integrated Social Studies learning through quizzes. Implication the STAD cooperative model, careful preparation is needed, especially when the answering group assessment is needed and preparing observation instruments along with clear rubrics during quiz activities.

Kata Kunci: Classical, Cooperative, Quiz

\section{Pendahuluan}

Salah satu bagian dari mata pelajaran IPS Terpadu yang kurang diminati siswa dalam belajar IPS Terpadu adalah materi sejarah . Mayoritas siswa menolak dan menghindari materi sejarah, alasannya siswa menganggap bahan ajar sejarah itu sulit, banyak menghafal dan kurang menarik karena cara penyampaiannya banyak dilakukan dengan ceramah (cerita).. Untuk menyikapi permasalahan tersebut, Guru harus memiliki beragam kemampuan yang dapat menunjang tugasnya agar tujuan pembelajaran dapat tercapai. Salah satu tuntutannya adalah memiliki kreasi dan daya inovatif dalam mengembangkan model-model pembelajaran yang menariksiswa. Sehingga pembelajaran yang semula dianggap sulit dan dianggap membosankan menjadi menarik. Tidak hanya menarik tetapi yang utama adalah mampu meningkatkan prestasi belajar siswa seperti yang tertuang dalam tuntutan kurikulum.

Menyikapi kondisi tersebut penulis sebagai guru IPS Terpadu kelas IX.A yang harus menyiapkan peserta didik menuju ujian akhir sekolah dan diharapkan mampu bersaing dalam mengikuti tes masuk Sekolah Lanjuta Tingkat Atas Unggulan, selalu berusaha memperbaiki pembelajaran dengan mengkondisikan pembelajaran yang memudahkan, mengasyikkan, dan menyenangkan bagi siswa. Usaha tersebut akan diwujudkan dalam suatu penelitian tindakan kelas yang akan menerapkan pembelajaran STAD dengan variasi bermain kuis.

Model pembelajaran STAD (Student Team Achievement Devision) adalah salah satu pembelajaran kooperatif yang dikembangkan berdasarkan teori belajar Kognitif-Konstruktivis yang diyakini oleh pencetusnya Vygotsky memiliki keunggulan yaitu fungsi mental yang lebih tinggi akan muncul dalam percakapan atau kerjasama antar individu. (Depag RI, 2004). STAD juga memiliki keunggulan bahwa siswa yang dikelompokkan secara heterogen berdasarkan kemampuan siswa terhadap Ilmu Pengetahuan Sosial akan terjadi interaksi yang positif dalam menyelesaikan masalah, seperti tutor sebaya dan lain-lain. Jika sebelumnya tidak ada interaksi antar individu, maka dalam STAD siswa dapat 
bekerja sama dalam menyelesaikan masalah sampai semua anggota kelompok dapat menyelesaikan masalah. Kelompok dikatakan tidak selesai jika ada anggotanya belum selesai.

\section{Metode Penelitian}

\subsection{Desain Penelitian}

Penelitian ini menggunakan rancangan Penelitian Tindakan Kelas (PTK). PTK adalah penelitian yang dilakukan oleh guru di dalam kelasnya sendiri melalui refleksi diri, dengan tujuan untuk memperbaiki kinerjanya sebagai guru, sehingga hasil belajar siswa menjadi meningkat (Wardani, 2005). Penelitian Tindakan Kelas sebagaimana dinyatakan oleh Kemmis dan Mc Taggart (dalam Yatim Riyanto, 2001) merupakan penelitian yang bersiklus, yang terdiri dari rencana, aksi, observasi, dan refleksi yang dilakukan secara berulang.

\subsection{Tempat dan Waktu Penelitian}

Tempat penelitian adalah tempat yang digunakan dalam melakukan penelitian untuk memperoleh data yang diinginkan. Penelitian ini bertempat di kelas IX.A M Ts Negeri Kota Sorong. Waktu penelitian adalah waktu berlangsungnya Penelitian dilaksanakan pada semester I tahun pelajaran 2017/2018 selama 2 bulan dari tanggal 12 Otober 2017 sampai dengan 11 Desember 2017.

\subsection{Teknik Pengumpulan Data}

Data-data yang diperlukan dalam penelitian ini diperoleh melalui Perencanaan, Tindakan, Observasi, Refleksi,

\subsection{Teknik Analisis Data}

Untuk mengalisis tingkat keberhasilan atau persentase keberhasilan siswa setelah proses belajar mengajar setiap putarannya dilakukan dengan cara memberikan evaluasi berupa soal tes tertulis pada setiap akhir siklus.

Analisis ini dihitung dengan menggunakan statistik sederhana yaitu:

1. Untuk menilai ulangan atu tes formatif

Peneliti melakukan penjumlahan nilai yang diperoleh siswa, yang selanjutnya dibagi dengan jumlah siswa yang ada di kelas tersebut sehingga diperoleh rata-rata tes formatif dapat dirumuskan:

$$
\bar{X}=\frac{\sum X}{\sum N}
$$

$$
\text { Dengan } \quad \begin{aligned}
: \bar{X} & =\text { Nilai rata-rata } \\
\Sigma \mathrm{X} & =\text { Jumlah semua nilai siswa } \\
\Sigma \mathrm{N} & =\text { Jumlah siswa }
\end{aligned}
$$




\section{Hasil dan Pembahasan}

\subsection{Hasil Penelitian}

\subsubsection{Perencanaan Tindakan}

Peneliti membentuk tim yang terdiri dari peneliti dan dua orang guru serta seorang pengambil gambar. Kemudian tim membahas segala kegiatan yang akan dilakukan pada kegiatan pembelajaran, antara lain:

1. Mempelajari langkah-langkah kegiatan pembelajaran beserta pembagianwaktunya.

2. Mempelajari instrumen yang akan digunakan merekam segala kejadian dan cara pengisiannya.

3. Mempelajari interaksi antar kelompok pada saat kegiatan kuis.

4. Mempelajari kode anggota kelompok beserta kartu anggota kelompok dan tugas masing-masing kelompok.

5. Pembagian tugas masing-masing anggota tim

6. Setelah semua anggota tim memahami berbagai kegiatan yang akan dilakukan, pertemuan diakhiri.

Sehari sebelum melakukan tindakan tepatnya hari Rabu tanggal 11Oktober 2017, peneliti/ guru kelas IXA memberi pengarahan kepada siswa bahwa besok akan diadakan pembelajaran STAD atau belajar kelompok. Kemudian peneliti membentuk kelompok menjadi tujuh kelompok, memberi nama kelompok sesuai tema belajar seperti: Seinendan, Keibondan, Fujinkai, Heiho, Syusyintai, Jawa Hokokai, dan PETA. Nama-nama kelompok ini diambil agar menarik dan mengingat bagian dari isi materi pembelajaran.

\subsubsection{Hasil Tiap Siklus}

Tabel 3.1. Hasil Pengamatan Belajar Klasikal Siklus I

\begin{tabular}{|c|c|c|c|c|c|c|c|c|}
\hline No. & $\mathrm{Na} \mathrm{m} \mathrm{a}$ & Nama & & & nis Kegiat & & & Ket \\
\hline & & Kelompok & $\begin{array}{c}\text { Meliha } \\
\mathrm{t}\end{array}$ & $\begin{array}{c}\text { Mendenga } \\
\mathrm{r}\end{array}$ & $\begin{array}{c}\text { Mencata } \\
\mathrm{t}\end{array}$ & $\begin{array}{c}\text { Bertany } \\
\text { a }\end{array}$ & $\begin{array}{c}\text { Menjawa } \\
\mathrm{b}\end{array}$ & Hadir \\
\hline 1 & $\begin{array}{l}\text { Ahmad } \\
\text { Wibowo }\end{array}$ & Seinendan & & & & & & 1 \\
\hline 2 & $\begin{array}{l}\text { Adelia } \\
\text { Adnan }\end{array}$ & & & & & & & \\
\hline 3 & Rendyansyah & & & & & & & 1 \\
\hline 4 & Deni Setiawan & & & & & & & \\
\hline 5 & Desilvi Ayu & Keibondan & & & & & & 1 \\
\hline 6 & Devi Luxpita & & & & & & & \\
\hline 7 & Fadila & & & & & & & \\
\hline 8 & Febriani & & & & & & & 1 \\
\hline 9 & Ganjar & & & & & & & 1 \\
\hline
\end{tabular}


Setiawan

10 Hildari Nur

11 Ida Kurnia

12 Sari

13 Irfandi

14 Mariani

15 Muh Akbar

16 Muh Hardinal Heiho

17 Nadya Safitri

18 Nia Naharia

19 Nur Hikmah

20 Rahmat Junaidi

Syusyintai

21 Rani Ramadani

22 Rezha Safitri

Rizki

23 Halmahera

Jawa

24 Sakira

Hokokai

25 Sarifah

Siti Nur

26 Aisyah

27 Rifal Zulkifli Peta

28 Ridho Maulana 1

29 Ulil Abshor

30 Zulfikar

J u m la h

Rata-rata

Jumlah siswa 30

Prosentase $=$ jumlah yang melakukan : jumlah yang hadir $\mathrm{x} 100$

Jumlah 170Rata-rata $=170: 3=56,67 \%$

Tabel 4.2 menunjukkan hasil pengamatan pengamat II dengan rata-rata 56,67\%.

Dari data di atas belum mencapai target yang diharapkan yaitu 60-70\%. Kegiatan bertanya dan mencatat masih belum ada sama sekali. Untuk siklus II perlu ada motivasi untuk melakukan kegiatan bertanya dan mencatat. 
Tabel 3.2. Hasil Pengamatan Belajar Kelompok Siklus I

\begin{tabular}{|c|c|c|c|c|c|c|c|c|}
\hline No. & $\mathrm{Nam} \mathrm{a}$ & $\mathrm{L} / \mathrm{P}$ & Nama & & Jenis Kegi & & & Ket \\
\hline & & & Kelompok & Kerjasama & Berpendapat & Semangat & $\begin{array}{l}\text { Hasil } \\
\text { Kerja }\end{array}$ & \\
\hline 1 & $\begin{array}{l}\text { Ahmad } \\
\text { Wibowo }\end{array}$ & $\mathrm{L}$ & Seinendan & 100 & 81 & 90 & 93 & \\
\hline 2 & $\begin{array}{l}\text { Adelia } \\
\text { Adnan }\end{array}$ & $\mathrm{P}$ & & & & & & \\
\hline 3 & Rendyansyah & $\mathrm{L}$ & & & & & & \\
\hline 4 & Deni Setiawan & $\mathrm{L}$ & & & & & & \\
\hline 5 & Desilvi Ayu & $\mathrm{P}$ & Keibondan & 93 & 90 & 90 & 100 & \\
\hline 6 & Devi Luxpita & $\mathrm{P}$ & & & & & & \\
\hline 7 & radila & $\mathrm{P}$ & & & & & & \\
\hline 8 & $\begin{array}{l}\text { Febriani } \\
\text { Ganjar }\end{array}$ & $\mathrm{P}$ & & & & & & \\
\hline 9 & Setiawan & $\mathrm{L}$ & & & & & & \\
\hline 10 & Hildari Nur & $\mathrm{P}$ & & & & & & \\
\hline 11 & $\begin{array}{l}\text { Ida Kurnia } \\
\text { Indah }\end{array}$ & $\mathrm{P}$ & Fujinkai & 100 & 85 & 95 & 100 & \\
\hline 12 & Purnama Sari & $\mathrm{P}$ & & & & & & \\
\hline 13 & Irfandi & $\mathrm{L}$ & & & & & & \\
\hline 14 & Mariani & $\mathrm{P}$ & & & & & & \\
\hline 15 & Muh Akbar & $\mathrm{L}$ & & & & & & \\
\hline 16 & Muh Hardinal & $\mathrm{L}$ & Heiho & 95 & 90 & 95 & 95 & \\
\hline 17 & Nadya Safitri & $\mathrm{P}$ & & & & & & \\
\hline 18 & Nia Naharia & $\mathrm{P}$ & & & & & & \\
\hline 19 & $\begin{array}{l}\text { Nur Hikmah } \\
\text { Rahmat }\end{array}$ & $\mathrm{P}$ & & & & & & \\
\hline 20 & $\begin{array}{l}\text { Junaidi } \\
\text { Rani }\end{array}$ & $\mathrm{L}$ & Syusyintai & 100 & 95 & 85 & 85 & \\
\hline 21 & Ramadani & $\mathrm{P}$ & & & & & & \\
\hline 22 & $\begin{array}{l}\text { Rezha Safitri } \\
\text { Rizki }\end{array}$ & $\mathrm{P}$ & & & & & & \\
\hline 23 & Halmahera & $\mathrm{L}$ & Jawa & & & & & \\
\hline 24 & Sakira & $\mathrm{P}$ & Hokokai & 98 & 90 & 95 & 90 & \\
\hline 25 & $\begin{array}{l}\text { Sarifah } \\
\text { Siti Nur }\end{array}$ & $\mathrm{P}$ & & & & & & \\
\hline 26 & Aisyah & $\mathrm{P}$ & & & & & & \\
\hline 27 & $\begin{array}{l}\text { Rifal Zulkifli } \\
\text { Ridho }\end{array}$ & $\mathrm{L}$ & Peta & 90 & 85 & 90 & 100 & \\
\hline 28 & Maulana & $\mathrm{L}$ & & & & & & \\
\hline 29 & Ulil Abshor & $\mathrm{L}$ & & & & & & \\
\hline \multirow[t]{2}{*}{30} & Zulfikar & $\mathrm{L}$ & & & & & & \\
\hline & $\mathrm{J} \mathrm{u} \mathrm{m} \mathrm{la} \mathrm{h}$ & & & 676 & 616 & 640 & 663 & 2595 \\
\hline
\end{tabular}




$\begin{array}{llllll}\text { Rata-rata } & 96,57 & 88,00 & 91,43 & 94,71 & 92,68\end{array}$

Prosentase $2595 / 4 / 7=92,68 \%$

Data di atas menunjukkan nilai yang sangat tinggi yaitu nilai rerata $92,68 \%$, jauh di atas yang diharapkan yaitu 70-80\%. Pada kegiatan kelompok ini memang hampir semua siswa aktif melakukan kegiatan belajar sesuai tugasnya masing-masing. Kemudian dilanjutkan dengan kegiatan kuis atau bertanya menjawab pada pertemuan kedua

Tabel : 4. 4 Rekapitulasi Hasil Observasi Kelompok Penanya Siklus II

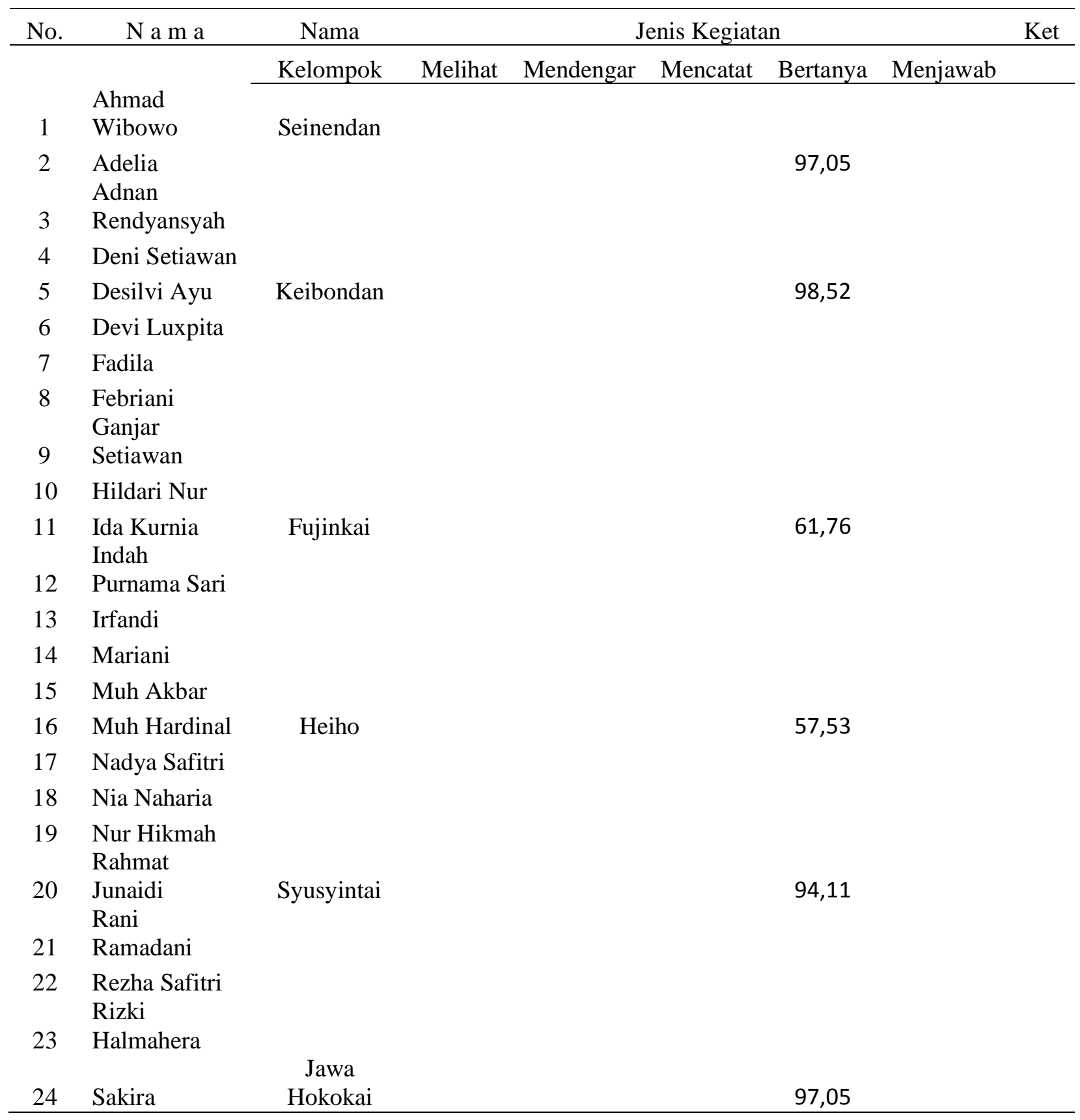




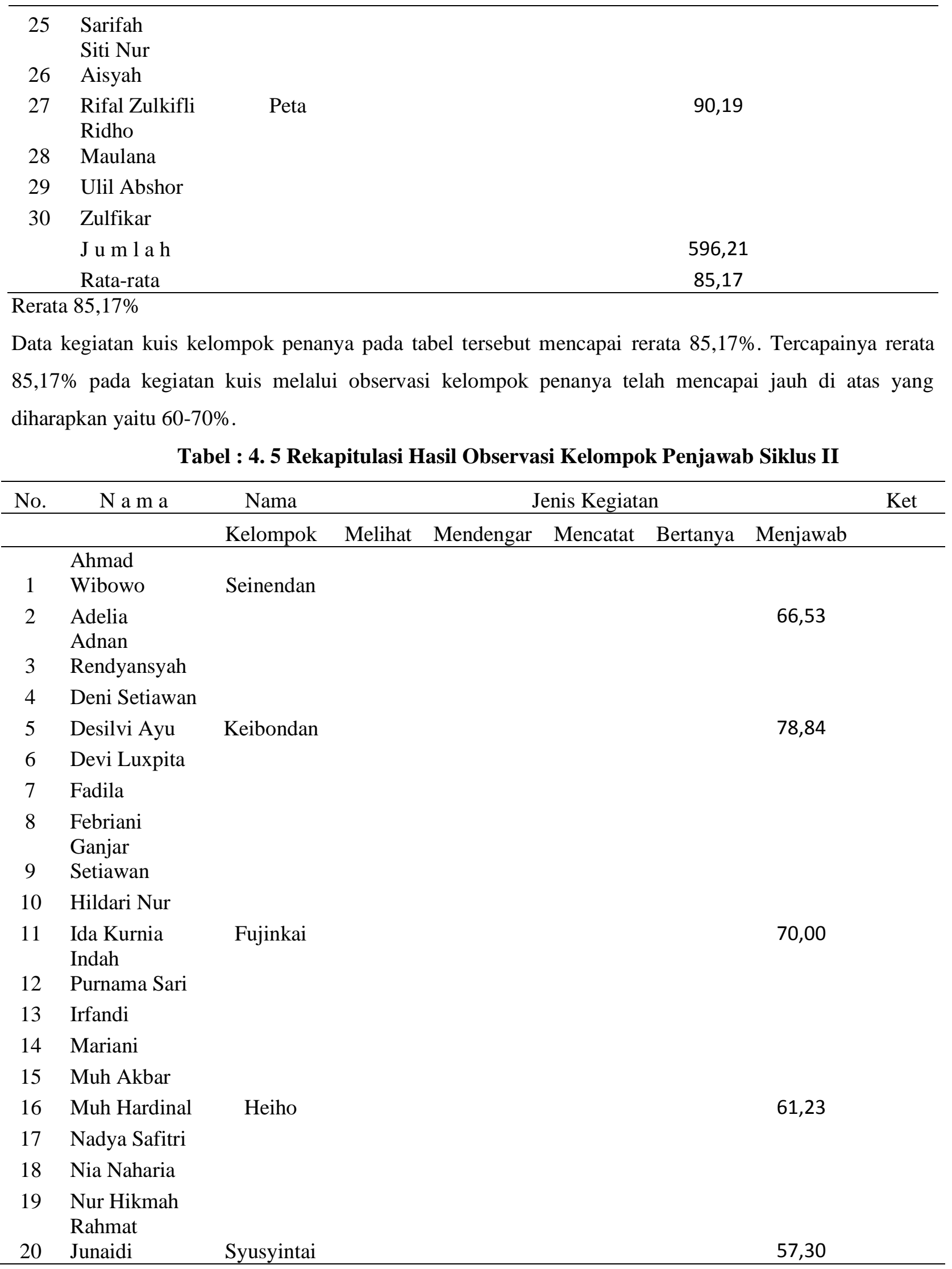




\begin{tabular}{llcc}
\hline & Rani & & \\
21 & Ramadani & & \\
22 & Rezha Safitri & & \\
& Rizki & & \\
23 & Halmahera & Jawa & 59,31 \\
24 & Sakira & Hokokai & \\
25 & Sarifah & & 58,92 \\
& Siti Nur & & \\
26 & Aisyah & & \\
27 & Rifal Zulkifli & Peta & \\
& Ridho & & \\
28 & Maulana & & 64,13 \\
29 & Ulil Abshor & & \\
30 & Zulfikar & & \\
& J u m l a h & & \\
\hline
\end{tabular}

Rerata $64,59 \%$

Tercapainya rata-rata $64,59 \%$ pada kegiatan kuis melalui observasi kelompok penjawab telah mencapai target yang diharapkan yaitu 60-70\%. Apabila diambil rerata dari kelompok penanya dan penjawab dapat dilihat sebagai berikut:

$(85,17 \%+64,59 \%): 2=72,88 \%$

Maka dapat diambil kesimpulan sementara bahwa proses pembelajaran melalui kegiatan kuis telah mencapai target yang telah ditentukan, bahkan mencapai di atas target yang diharapkan.

Adapun hasil belajar siswa pada siklus I dapat dilaporkan sebagai berikut:

Ada dua orang siswa yang tidak hadir pada saat evaluasi hasil belajar karena sakit. Sehingga jumlah siswa yang hadir 24 siswa. 16 siswa telah mencapai ketuntasan belajar atau 66,66\% telah mencapai nilai 60 - >60. Masih ada 8 siswa yang belum mencapai ketuntasan belajar atau 33,33\% masih mendapat nilai 50\% siswa belum berhasil menyelesaikan dengan benar. Maka diperlukan penjelasan ulang atau remidial klasikal tentang soal nomor 9 dan 10.

Tabel : 4.5 Hasil Pengamatan Belajar Klasikal Siklus III

\begin{tabular}{|c|c|c|c|c|c|c|c|c|}
\hline No. & $\mathrm{N}$ a m a & $\mathrm{L} / \mathrm{P}$ & Nama & \multicolumn{4}{|c|}{ Jenis Kegiatan } & Ket \\
\hline & & & Kelompok & Kerjasama & Berpendapat & Semangat & $\begin{array}{l}\text { Hasil } \\
\text { Kerja }\end{array}$ & \\
\hline 1 & $\begin{array}{l}\text { Ahmad } \\
\text { Wibowo }\end{array}$ & $\mathrm{L}$ & Seinendan & 96 & 82 & 88 & 85 & \\
\hline 2 & Adelia & $\mathrm{P}$ & & & & & & \\
\hline 3 & Adnan & $\mathrm{L}$ & & & & & & \\
\hline
\end{tabular}




\begin{tabular}{|c|c|c|c|c|c|c|c|c|}
\hline & Rendyansyah & & & & & & & \\
\hline 4 & Deni Setiawan & $\mathrm{L}$ & & & & & & \\
\hline 5 & Desilvi Ayu & $\mathrm{P}$ & Keibondan & 80 & 85 & 90 & 90 & \\
\hline 6 & Devi Luxpita & $\mathrm{P}$ & & & & & & \\
\hline 7 & Fadila & $\mathrm{P}$ & & & & & & \\
\hline 8 & $\begin{array}{l}\text { Febriani } \\
\text { Ganjar }\end{array}$ & $\mathrm{P}$ & & & & & & \\
\hline 9 & Setiawan & $\mathrm{L}$ & & & & & & \\
\hline 10 & Hildari Nur & $\mathrm{P}$ & & & & & & \\
\hline 11 & $\begin{array}{l}\text { Ida Kurnia } \\
\text { Indah }\end{array}$ & $\mathrm{P}$ & Fujinkai & 95 & 85 & 90 & 96 & \\
\hline 12 & Purnama Sari & $\mathrm{P}$ & & & & & & \\
\hline 13 & Irfandi & $\mathrm{L}$ & & & & & & \\
\hline 14 & Mariani & $\mathrm{P}$ & & & & & & \\
\hline 15 & Muh Akbar & $\mathrm{L}$ & & & & & & \\
\hline 16 & Muh Hardinal & $\mathrm{L}$ & Heiho & 90 & 84 & 82 & 80 & \\
\hline 17 & Nadya Safitri & $\mathrm{P}$ & & & & & & \\
\hline 18 & Nia Naharia & $\mathrm{P}$ & & & & & & \\
\hline 19 & $\begin{array}{l}\text { Nur Hikmah } \\
\text { Rahmat }\end{array}$ & $\mathrm{P}$ & & & & & & \\
\hline 20 & $\begin{array}{l}\text { Junaidi } \\
\text { Rani }\end{array}$ & $\mathrm{L}$ & Syusyintai & 85 & 84 & 80 & 82 & \\
\hline 21 & Ramadani & $\mathrm{P}$ & & & & & & \\
\hline 22 & $\begin{array}{l}\text { Rezha Safitri } \\
\text { Rizki }\end{array}$ & $\mathrm{P}$ & & & & & & \\
\hline 23 & Halmahera & $\mathrm{L}$ & Jawa & & & & & \\
\hline 24 & Sakira & $\mathrm{P}$ & Hokokai & 78 & 80 & 78 & 83 & \\
\hline 25 & $\begin{array}{l}\text { Sarifah } \\
\text { Siti Nur }\end{array}$ & $\mathrm{P}$ & & & & & & \\
\hline 26 & Aisyah & $\mathrm{P}$ & & & & & & \\
\hline 27 & $\begin{array}{l}\text { Rifal Zulkifli } \\
\text { Ridho }\end{array}$ & $\mathrm{L}$ & Peta & 75 & 80 & 82 & 84 & \\
\hline 28 & Maulana & $\mathrm{L}$ & & & & & & \\
\hline 29 & Ulil Abshor & $\mathrm{L}$ & & & & & & \\
\hline \multirow[t]{3}{*}{30} & Zulfikar & $\mathrm{L}$ & & & & & & \\
\hline & $\mathrm{J} \mathrm{u} \mathrm{m} \mathrm{la} \mathrm{h}$ & & & 599 & 580 & 590 & 600 & 2369 \\
\hline & Rata-rata & & & 85,57 & 82,86 & 84,29 & 85,71 & 84,61 \\
\hline
\end{tabular}

Jumlah siswa 30

Prosentase $=$ jumlah yang melakukan : jumlah yang hadir $\mathrm{x} 100$

Rerata : $2369: 4: 7=84,61 \%$ 
Tabel 4.12 menunjukkan bahwa dari hasil pengamatan pembelajaran klasikal siklus III telah berhasil mencapai rerata $84,61 \%$. Keberhasilan tersebut telah dapat memenuhi target yang ditentukan yaitu $60 \%-70 \%$ dan mengalami kemajuan yang cukup signifikan dibandingkan siklus I yang baru mencapai $54,22 \%$ dan siklus II telah mencapai $66,15 \%$.

Tabel : 4.6 Hasil Pengamatan Belajar Kelompok Siklus III

\begin{tabular}{|c|c|c|c|c|c|c|c|c|}
\hline No. & $\mathrm{Nam} \mathrm{a}$ & $\mathrm{L} / \mathrm{P}$ & Nama & & Jenis Kegi & & & Ket \\
\hline & & & Kelompok & Kerjasama & Berpendapat & Semangat & $\begin{array}{l}\text { Hasil } \\
\text { Kerja }\end{array}$ & \\
\hline 1 & $\begin{array}{l}\text { Ahmad } \\
\text { Wibowo }\end{array}$ & $\mathrm{L}$ & Seinendan & 92 & 97 & 97 & 98 & \\
\hline 2 & $\begin{array}{l}\text { Adelia } \\
\text { Adnan }\end{array}$ & $\mathrm{P}$ & & & & & & \\
\hline 3 & Rendyansyah & $\mathrm{L}$ & & & & & & \\
\hline 4 & Deni Setiawan & $\mathrm{L}$ & & & & & & \\
\hline 5 & Desilvi Ayu & $\mathrm{P}$ & Keibondan & 98 & 98 & 98 & 100 & \\
\hline 6 & Devi Luxpita & $\mathrm{P}$ & & & & & & \\
\hline 7 & Fadila & $\mathrm{P}$ & & & & & & \\
\hline 8 & $\begin{array}{l}\text { Febriani } \\
\text { Ganjar }\end{array}$ & $\mathrm{P}$ & & & & & & \\
\hline 9 & Setiawan & $\mathrm{L}$ & & & & & & \\
\hline 10 & Hildari Nur & $\mathrm{P}$ & & & & & & \\
\hline 11 & $\begin{array}{l}\text { Ida Kurnia } \\
\text { Indah }\end{array}$ & $\mathrm{P}$ & Fujinkai & 98 & 98 & 98 & 100 & \\
\hline 12 & Purnama Sari & $\mathrm{P}$ & & & & & & \\
\hline 13 & Irfandi & $\mathrm{L}$ & & & & & & \\
\hline 14 & Mariani & $\mathrm{P}$ & & & & & & \\
\hline 15 & Muh Akbar & $\mathrm{L}$ & & & & & & \\
\hline 16 & Muh Hardinal & $\mathrm{L}$ & Heiho & 98 & 98 & 98 & 100 & \\
\hline 17 & Nadya Safitri & $\mathrm{P}$ & & & & & & \\
\hline 18 & Nia Naharia & $\mathrm{P}$ & & & & & & \\
\hline 19 & $\begin{array}{l}\text { Nur Hikmah } \\
\text { Rahmat }\end{array}$ & $\mathrm{P}$ & & & & & & \\
\hline 20 & $\begin{array}{l}\text { Junaidi } \\
\text { Rani }\end{array}$ & $\mathrm{L}$ & Syusyintai & 98 & 98 & 98 & 98 & \\
\hline 21 & Ramadani & $\mathrm{P}$ & & & & & & \\
\hline 22 & $\begin{array}{l}\text { Rezha Safitri } \\
\text { Rizki }\end{array}$ & $\mathrm{P}$ & & & & & & \\
\hline 23 & Halmahera & $\mathrm{L}$ & Jawa & & & & & \\
\hline 24 & Sakira & $\mathrm{P}$ & Hokokai & 98 & 98 & 98 & 98 & \\
\hline 25 & Sarifah & $\mathrm{P}$ & & & & & & \\
\hline
\end{tabular}




\begin{tabular}{lllcccccc}
\hline \multirow{2}{2}{6} & Siti Nur & Aisyah & P & & & & & \\
27 & Rifal Zulkifli & L & Peta & 98 & 98 & 98 & 98 \\
& Ridho & & & & & & \\
28 & Maulana & L & & & & & \\
29 & Ulil Abshor & L & & & & & \\
30 & Zulfikar & L & & & & & & \\
& J u m l a h & & 680 & 685 & 685 & 692 & 2742 \\
& Rata-rata & & 97,14 & 97,86 & 97,86 & 98,86 & 97,93 \\
\hline
\end{tabular}

Tabel di atas menunjukkan angka rerata dari belajar kelompok sebesar 97,93\%. Sedangkan pada siklus II belajar kelompok telah menunjukkan rerata 92,68\%. Maka terdapat peningkatan 5,06\% dari siklus II. Peningkatan kegiatan kelompok ini disebabkan karena hampir semua kelompok mencapai keaktifan 100\% kecuali kelompok A dan F karena masing-masing kelompok tersebut ada satu siswa yang kurang berpendapat dalam diskusi kelompok

Tabel: 4.7 Rekapitulasi Peningkatan Proses Pembelajaran dan Hasil Belajar PROSES PERKEMBANGAN EMBELAJARAN

DARI SIKLUS I KE SIKLUS II

\begin{tabular}{|c|c|c|c|c|c|c|}
\hline JENIS & \multirow{2}{*}{\multicolumn{2}{|c|}{ A W A L }} & \multicolumn{2}{|c|}{ KEMAJUAN YANG } & \multicolumn{2}{|c|}{ KENAIKAN } \\
\hline TINDAKAN & & & & DICAPAI & & \\
\hline KLASIKAL & 52,22 & $\%$ & 66,17 & $\%$ & 13,95 & $\%$ \\
\hline STAD & 91,66 & $\%$ & 92,85 & $\%$ & 1,19 & $\%$ \\
\hline KUIS & 74,82 & $\%$ & 86,17 & $\%$ & 11,35 & $\%$ \\
\hline
\end{tabular}

DARI SIKLUS II KE SIKLUS III

\begin{tabular}{|c|c|c|c|}
\hline JENIS & A W A L & KEMAJUAN YANG & KENAIKAN \\
\hline TINDAKAN & & DICAPAI & \\
\hline KLASIKAL & $66,17 \%$ & $84,61 \%$ & $18,44 \%$ \\
\hline STAD & $92,85 \%$ & $97,91 \%$ & $5,06 \%$ \\
\hline
\end{tabular}




$\begin{array}{lllllll}\text { KUIS } & 86,17 & \% & 92,77 & \% & 6,6 & \%\end{array}$

\subsection{Pembahasan}

Rekapitulasi peningkatan proses pembelajaran dan hasil belajar pada tabel 4.17 dapat ditunjukkan kemajuan-kemajuan yang dicapai dari seluruh kegiatan mulai dari siklus I, siklus II, dan siklus III. Pada pembelajaran klasikal selain mengalami peningkatan dari siklus ke siklus, kenaikan itu sendiri juga mengalami peningkatan yaitu dari 13,95 menjadi 18,44. Begitu juga pada kegiatan kelompok kooperatif STAD, dari kenaikan 1,19 menjadi 5,06.

Pembelajaran kuis mengalami peningkatan dari siklus ke siklus, namun kenaikannya turun dari 11,35 menjadi 6,6. Hal ini terjadi mungkin karena pelaksanaan penelitian ini pada saat siswa belajar pada jam terakhir, sedangkan kuis banyak memerlukan kegiatan fisik, sehingga terjadi penurunan.

Hasil belajar terjadi kenaikan dari siklus ke siklus dan terjadi peningkatan kemajuan dari kondisi semula ke siklus I adalah 7,2, dari siklus I ke siklus II 7,3 dan dari siklus II ke siklus III 7,31. Peningkatan kenaikan memang sangat tipis, namun karena kompetensi dasar yang harus dicapai juga semakin sulit maka terjadinya kenaikan tersebut juga cukup berarti.

\section{Kesimpulan dan Saran}

\subsection{Kesimpulan}

Hasil analisis data dan pembahasan dapat menunjukkan beberapa kemajuan yang dicapaiselama pembelajaran baik melalui pembelajaran klasikal, model kooperatif STAD, bermain kuis, maupun hasil belajar. Maka hasil penelitian tindakan kelas ini dapat ditarik kesimpulan sebagai berikut:

1. Pembelajaran model kooperatif STAD dapat meningkatkan prestasi belajar siswa tentang Perang Dunia II (termasuk pendudukan Jepang) serta pengaruhnya terhadap keadaan sosial, ekonomi, dan politik di Indonesia.

2. Bermain kuis dapat meningkatkan prestasi hasil belajar siswa tentang Perang Dunia II (termasuk pendudukan Jepang) serta pengaruhnya terhadap keadaan sosial, ekonomi, dan politik di Indonesia

\subsection{Saran}

Berdasarkan beberapa kemajuan yang dicapai dan hasil simpulan penelitian ini, maka perlu disampaikan beberapa saran yang berkaitan dengan pemanfaatan hasil penelitian tindakan kelas yang menerapkan pembelajaran Model Kooperatif STAD dengan variasi KUIS. Beberapa saran yang perlu disampaikan adalah: 
1. Bagi teman-teman guru, untuk mengatasi permasalahan pembelajaran IPS Terpadu yang cenderung tidak disukai oleh siswa, maka sebagai alternatif penyelesaiannya adalah menerapkan model kooperatif STAD.

2. Juga untuk teman-teman guru, untuk menerapkan Strategi pembelajaran kuis seperti pada penelitian ini diperlukan persiapan yang matang, terutama pada saat penilaian kelompok penjawab diperlukan bantuan dari siswa yang pandai untuk membantu guru mengerjakan soalsoal yang dibuat oleh temannya.

3. Bagi peneliti yang ingin melakukan penelitian lanjutan sesuai dengan penelitian ini juga disarankan agar membuat persiapan yang lebih sempurna terutama dalam mempersiapkan instrumen pengamatan beserta rubrik-rubrik yang jelas pada saat kegiatan kuis.

\section{Daftar Pustaka}

Arikunto,Suharsimi \& Suharjono \& Supardi. 2006, Penelitian Tindakan Kelas. Jakarta: Bumi Aksara.

Departemen Agama RI. 2001. Bahan Penataran ( Modul Metodologi Pendidikan Agama Islam)Jakarta: Direktorat Jendral Pembinaan Kelembagaan Agama Islam.

Hasibuan \& Mujiono. 2004. Proses Belajar Mengajar. Bandung: Remaja Rosdakarya.

Nur, Mohammad. 1998. Teori Pembelajaran Kognitif. Surabaya: PPS IKIP Surabaya.

Undang-Undang Republik Indonesia Nomor 20 Tahun 2003 tentang Sistem Pendidikan Nasional. 2003. Jakarta: Cemerlang.

Wardani, I.G.A.K. 2005. Penelitian Tindakan Kelas. Jakarta: Universitas terbuka Departemen Pendidikan Nasional.

Riyanto, Yatim. 2001. Metodologi Penelitian Pendidikan. Surabaya: Penerbit SIC.

Yuwono, Trisno \& Abdullah Pius. 1994. Kamus Lengkap Bahasa Indonesia Praktis. Surabaya: Arkola. 